https://doi.org/10.31713/m1028

\title{
MODELING THE PROCESS OF DISINTEGRATION OF SOLID MATERIALS BY ASYMMETRIC LOADING IN CRUSHING MACHINES IN ORDER TO FIND WAYS TO REDUCE ENERGY COSTS
}

\author{
Vasiliev L.M. \\ Institute of Geotechnical Mechanics. M.S. Polyakov National \\ Academy of Sciences of Ukraine, Dnipro, doc. tech. sciences, \\ professor, led. scientific. sotr, Ukraine \\ Vasiliev D.L. \\ Institute of Geotechnical Mechanics named after M.S. Polyakov \\ National Academy of Sciences of Ukraine, Dnipro, doc. tech. \\ Sciences, Art. scientific. sotr, Ukraine
}

\section{Malich M.G.}

National Metallurgical Academy of Ukraine, Dnipro, Cand. tech. Sci., Associate Professor, Associate Professor, Ukraine

\section{Annotation}

Subject of study. the processes of cracking and destruction of rocks under the action of the working bodies of machines for disintegration.

Methodology. A complex method of generalizing the laws of the theory of elasticity and plasticity was used; theoretical and experimental confirmation of the regularities of the distribution of contact normal and tangential stresses, equations of the limiting state of materials based on the Coulomb strength criterion; slip line theory; comparison of theoretical results with experimental diagrams "normal stresslongitudinal deformation" of samples; facts and phenomena of destruction of rocks; generalization of the theoretical regularities arising from the power contact of the tool with the rock in crushers.

Purpose. Reducing energy consumption and increasing the efficiency of rock disintegration by controlling its stress-strain state in crushers on the basis of mathematical modeling and using the established regularities of stresses and deformations in rocks when interacting with a working tool.

Output. In the contact area, with an increase in the tangential load, the zone of uniform compression of the material decreases, the depth of the most stressed point approaches the contact surface. There is a significant zone of shear deformations, which are the decisive factor in crack initiation. The development of the crack in depth and complete destruction occurs along the shear lines. Such conditions of rock loading are observed in jaw crushers with complex jaw movement, in cone crushers, in roller crushers with different roll rotation speeds and correspond to the model of the most effective sliding compression. The creation of asymmetric loading conditions using the forces of contact friction, frictional and strength characteristics of the destroyed material can reduce the energy consumption of disintegration. 


\section{Introduction}

The dynamics of changes in the quality of mining ores of nonferrous and ferrous metals, coal, mining and chemical raw materials and other solid minerals over the past twenty-five years shows that the content of useful components in them has sharply decreased. It is known that enrichment is carried out by separating mineral associations with certain technological properties in terms of mineral composition.

The existing mass disintegration technologies have low efficiency (primarily energy efficiency): even the most advanced of them "use" less than $1 \%$ of the supplied energy for useful work. And this despite the fact that energy costs for crushing and crushing rocks, already today account for a tenth of all electricity produced in the country, continue to grow [1].

If we take into account that, in addition to the processing of mineral raw materials, the processes of destruction of solid materials are widely used in construction, pulp and paper production, for the preparation of wood, in the food industry, the production of medicines, in the processing of household and industrial waste and in a number of other industries, then we can conclude that they are one of the most widespread and at the same time energy-, metal-, capitaland labor-intensive technological processes in the industrial economy. Along with this, the existing methods of disintegration do not meet a number of requirements of industrial production.

First, traditional degradation processes are characterized by low selectivity. This is expressed in the fact that when separating multicomponent materials, it is necessary to violate the integrity of the components themselves, which adversely affects their technical and technological properties.

Secondly, traditional crushing and grinding processes are not suitable for the destruction of all solid materials: especially strong materials (metals, hard alloys, raw materials for powder metallurgy, abrasive, ceramic, etc.) are destroyed ineffectively or not at all by known methods. At the same time, the need for the disintegration of such materials is beyond doubt.

Thirdly, for some technologies, in particular, in the enrichment of minerals and in the preparation of mining, metallurgical and 
chemical raw materials, equipment for disintegration, which is serially produced, does not provide the necessary disintegration efficiency.

In this regard, there is a need to control the processes of disintegration and the key to this is the assessment of the bearing capacity of the rock under various types of impact of working tools.

Researchers [2] to assess the bearing capacity of the rock use diagrams "normal stress - longitudinal deformation", which are built on special presses with increased rigidity under uniaxial and volumetric compression of samples. However, the use in practical calculations of the ultimate strength and residual fracture strength of samples obtained on the basis of these diagrams are relative values due to the influence of the scale effect, which is observed not only on fractured, but also on samples without cracks and depends on their size. In addition, it was revealed that, for unknown reasons, under uniaxial compression, five forms of fracture of samples are formed, which have a different character of these diagrams.

As a result of the above, it follows that the mechanism of crack initiation and subsequent destruction of a deformable body has not yet been fully disclosed. In this case, internal and contact friction is not always taken into account, analytical methods for calculating and constructing diagrams "normal stress - longitudinal deformation" with the use of indices of rock properties available for experimental determination, which make it possible to determine the stress-strain state of rock pieces under the action of a working body to find ways of the most effective destruction.

Therefore, the development of mathematical models of the deformation of bodies when a working tool collides with a rock, the appearance of the first cracks, their development in a brittle body to control their stress-strain state in disintegration processes for the preparation of charge materials is an urgent scientific problem, which is of great practical importance for mining and metallurgical complex of the country.

Interactions of the tool with the hole under normal and tangential loading

Let us consider the interaction of working tools - elements of corrugation of armor plates in the case of external forces $Q$, along the normal to the line of contact of corrugation with destructible material 
with a uniform distribution along the line of contact of tangential forces $Q_{1}$ (Fig. 1) [3].

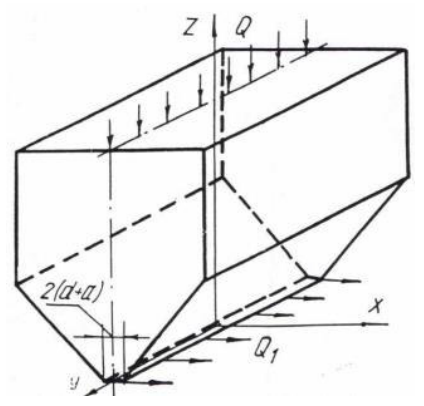

Pict. 1. Design scheme for applying loads

The solution to this problem is associated with significant mathematical difficulties [4]. The authors of $[1,3]$ obtained an approximate solution to such a problem, taking into account the following assumptions: contact pressure is distributed over an ellipse in the zone of contact of surfaces; shear loads are proportional to normal

$$
\frac{Q_{1}}{Q}=\frac{q_{\max }}{p^{\max }}=\varphi=\mathrm{const} .
$$

The stress state of the rock was determined by the values of the stress components

$$
\begin{aligned}
& \sigma_{x}=q_{\max }\left(2 e^{-\alpha} \cos \beta_{0}-\operatorname{Sh} a \sin \beta_{0} \frac{\sin 2 \beta_{0}}{C h 2 \alpha-\cos 2 \beta_{0}}\right) \\
& \sigma y=2 \mu q_{\max } e^{-\alpha} \cos \beta_{0} \\
& \sigma_{x}=q_{\max } \operatorname{Sh} a \sin \beta_{0} \frac{\sin 2 \beta_{0}}{C h 2 \alpha-\cos 2 \beta_{0}} . \\
& \tau_{x z}=q_{\max }\left(e^{-\alpha} \cos \beta_{0}-\operatorname{Sh} a \sin \beta_{0}\left(1-\frac{\operatorname{Sh} 2 \beta_{0}}{C h 2 \alpha-\cos 2 \beta_{0}}\right)\right) .
\end{aligned}
$$

Here $\sigma_{y}$ is found from the plane strain equation: $\sigma_{y}=\mu\left(\sigma_{x}+\sigma_{z}\right)$.

$\mu$ - is Poisson's ratio; $\alpha$ and $\beta$ - are elliptic coordinates, the link of which with rectangular coordinates $x$ and $y$ using hyperbolic circular functions is determined as follows

$$
x=(a+d) \mathrm{Chacos} \beta_{0}, \quad z=(a+d) \mathrm{Shasin} \beta_{0}
$$


Graphical interpretation of the solution obtained by the authors [1], which describes the stress state of the elements of the tool and the rock in the zone of their joint contact in the form of a diagram of the distribution of $\sigma$ over the contact zone, obtained at $\mu=0.2$, are shown in Fig. 2.
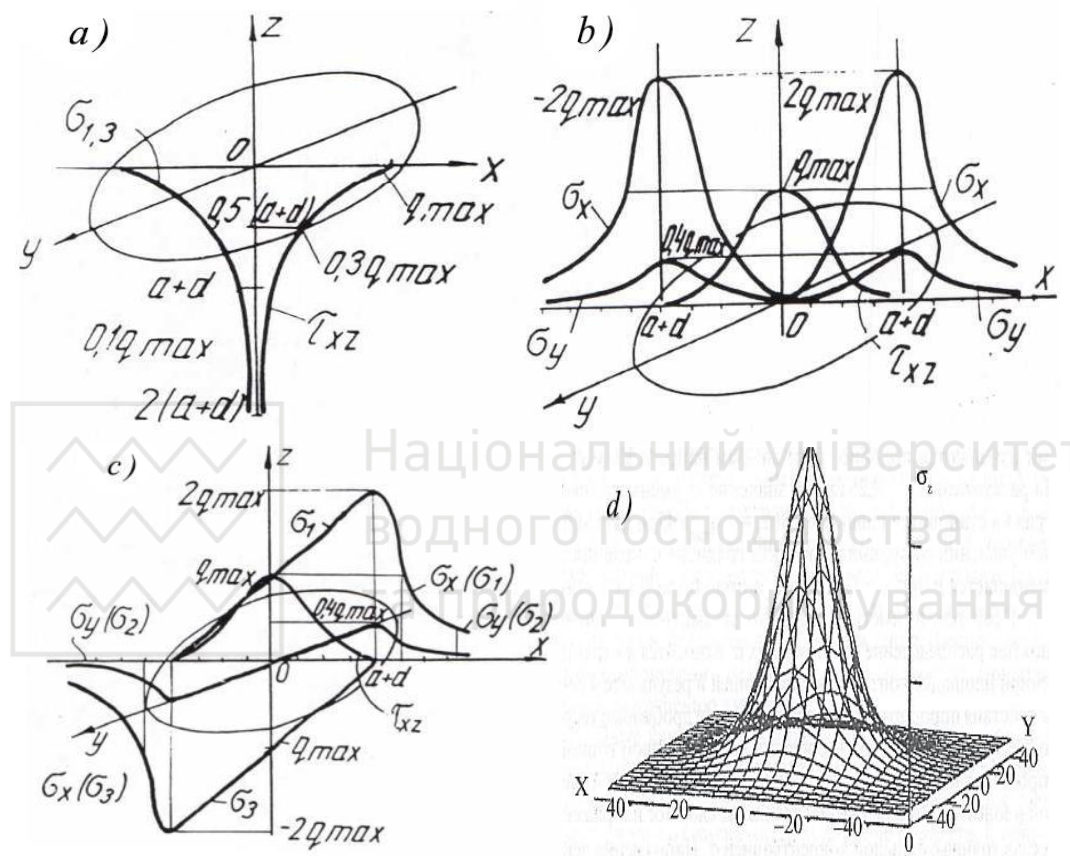

Fig. 2. Distribution of stresses over the contact zone: $a$ - vertical plane; $b$ horizontal plane - normal and shear stresses; $c$ - horizontal plane - principal and shear stresses. $d$ - diagram of normal stresses from a concentrated force in an elastic half-space

In the vertical plane passing through the middle of the contact, $\sigma_{1}$, $\sigma_{2}, \tau_{x y}$ act (Fig. 2). The nature of the separation of these stresses in the vertical plane is similar. Their maximum values, equal to $Q_{\max }$, take place on the contact surface $(z=0)$.

In the depths of a piece of rock, the values of $\sigma$ decrease intensively. Already at a distance $z=0.5(a+d)$ from the surface, the 
acting stresses decrease by about 3 times and amount to $0.3 q_{\max }$. At a depth of $z=a+d$ they decrease by a factor of 10 , and at a distance $z=2(a+d)$ from the contact zone, the values of $\sigma$ and $\tau$ tend to zero.

In the horizontal plane, including the contact zone, the main, normal and shear stresses act (Fig. 3). The normal stress $\sigma_{x}$ within the contact area varies from $\sigma_{x}=2 q_{\max }$ at the boundary of the area to 0 at its center. When going from the center to the periphery of the contact, $\sigma_{x}$ intensively expands and change sign to the opposite. At the opposite boundary of the contact, they again increase to $\sigma_{x}=$ $2 q_{\max }$.

Beyond the boundary of the contact zone (to the left and to the right of it), $\sigma_{x}$ first sharply decreases, but then the diagram calms down and tends to zero at $x>1.5(a+d)$. The distribution of stresses $\sigma_{y}$ over the horizontal plane is similar to that considered above with the only difference that the absolute value of $\sigma_{y}$ is less than $\sigma_{x}$ by $\mu$. The nature of the change in stresses $\sigma_{x}$ and $\sigma_{y}$ is the same both within the contact plane and outside it. Shear stresses have maximum values $\tau_{\max }=q_{\max }$ in the center of the contact area. To the boundary of the contact zone, they decrease and take zero values.

The main stresses are $\sigma_{1}, \sigma_{2}, \sigma_{3}$. The stress $\sigma_{1}$ along the contact area changes from $\sigma_{1}=2 q_{\max }$ to 0 . Zero values of $\sigma_{1}$ have on the side of the action of the force $Q_{1}$. On the opposite side, at the contact boundary, $\sigma_{1}$ reach maximum values, outside the site, they decrease intensively and, at $x>1.5(a+d)$, approach zero values. In this case, $\sigma_{2}$ are distributed over the contact area in full accordance with the stresses $\sigma_{y}$, both in terms of the values of the acting stresses and the nature of their distribution. For $\sigma_{3}$ in the horizontal plane, the character of change in stresses $\sigma_{l}$ is inherent, but has an inverted (mirror) reflection. From the side of the application of the load $Q_{1}$ at the contact boundary $\sigma_{3}$ has a maximum value of $\sigma_{3}=2 q_{\max }$ then they intensively decrease along the contact area and reach zero values on the opposite contact contour. Outside the contact area, $\sigma_{3}$ of their maximum values change like the normal stress $\sigma_{x}$. At a distance of $x=0.25(a+d)$, the value of $\sigma_{3}$ decreases by 2 times and becomes equal to $q_{\max }\left(\sigma_{x}=q_{\max }\right)$. With further distance from the contact boundary, the stress gradient decreases and at $x>1.5(a+d) \sigma_{3}$ 
approaches zero. Such a complex distribution of acting stresses occurs over a small contact surface (units of $\mathrm{mm}$ ).

Knowing the stress state of the working elements and a piece of rock in the zone of their contact from the action of the normal load and from the tangential forces $Q_{1}$, it becomes possible to obtain the general stress state by the superposition method (for example, by the total value of $\sigma_{e q}$ ). The maximum values of contact stresses, in absolute value, increase with the growth of both normal and tangential loads. In the presence of $Q_{1}$, the values of $\sigma$ and $\tau$ increase significantly, a zone of shear deformations arises, which are the decisive factor in the initiation of a crack. Thus, it has been shown that, in the fracture mechanism, it is these stresses that determine the zone of crack initiation, through which fracture and displacement of the rock occur, which leads to its further destruction.

\section{Fracture of a prismatic specimen by normal and shear stresses.}

The development of destruction deep into the rock is different. To describe this process, the diagrams "longitudinal stress - longitudinal deformation" obtained for prismatic specimens under uniaxial compression are used. [5.6]. Analytical constructions of such diagrams are also used [2,7]. In real conditions of disintegration, there may be other conditions, for example, in millstones or in cone crushers where, in addition to normal, oppositely directed contact shear stresses act.

Based on the parameters of the diagrams mentioned, it is possible to determine the specific fracture energy of the sample according to the well-known formula

$$
E_{d}=\frac{p^{2}}{2 E},
$$

where $p$ - is the specific force on the bearing area; $E$ - is the modulus of elasticity of the material.

Let us take one [8] of the five known [9], the simplest form of destruction of prismatic rock samples - truncated-wedge (Fig. 3). 
Fig. 3. Experimental truncated-wedge fracture

The truncated-wedge form of fracture of rock samples is characterized by the absence of intersection of the crack with the vertical line of symmetry (Fig. 4). When the specimen is compressed, symmetric contact shear stresses $\tau_{c}$ against transverse deformation arise. The sign of the contact shear stresses in the upper part of the left half of the specimen is taken with a "plus", for the lower part - with a "minus". For the right half of the sample, the signs of $\tau_{c}$ are assumed to be opposite. Since the lateral surfaces of the specimen acquire a convex shape due to deformation, we apply the rule of pairing of tangential stresses at the corner points. The condition for the limiting state at the crack tip is the equality of the ultimate shear strength of the material to the active shear stress minus losses for internal and contact friction according to the Coulomb criterion

$$
k_{n}=\left|\tau_{\alpha}\right|-\mu \sigma_{\alpha},
$$

where $k_{n}$ - is the ultimate shear strength of the rock at the crack tip at the TEMECN (trajectory of the maximum effective shear stresses) $\xi$; $\left|\tau_{\alpha}\right|$ - active shear stress on TMEKN; $\mu$ and $\rho=\operatorname{arctg} \mu$ - coefficient and angle of internal friction; $\sigma_{\alpha}$ - is the normal stress on the TMECN $\xi$. We assume that cracks (Fig. 4) develop according to ТМЭКН: - to the left according to ТМЭКН $\xi_{\text {l, }}$ - to the right along ТМЭКН $\xi_{r}$. Since the TMEDS are symmetric, we give a description of the left TMEDN $\xi_{1}$. The angle of inclination of TMEKN $\xi_{1}$. according to the Coulomb strength criterion is determined by the formula.

$$
\alpha_{\pi}=\frac{\pi}{4}+\frac{\rho}{2}+\beta_{\xi_{1}}
$$

As the crack develops, part of the material comes out of the load (Fig. 4). 

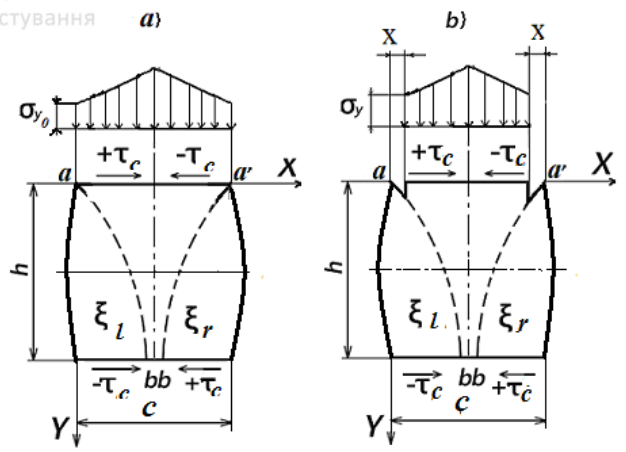

Fig. 4. Diagrams of diagrams of contact normal loads and crack propagation according to TMEKN $\xi$ with a symmetric distribution of shear stresses: $a$ - in an elastic state; $b$ - at the time of crack development

Knowing the values of the coordinates of the crack tip on the TMECN $\xi_{1}$ at each moment of its development, it is possible to determine the bearing part of the sample material area, equal to the initial unit length of the latter minus the part that came out from under the load. Then a single bearing area of the specimen with the development of two symmetric cracks will be

$$
a_{2}=c-2 x \text {. }
$$

On the load-bearing part of the specimen with cracks emerging from under the load, the distribution of the contact load and the specific force change, the values of which we need to calculate the specific energy of destruction according to formula (3). To determine the specific force, it is necessary to know the regularity of the distribution of contact normal stresses. Regularities of the distribution of contact normal and tangential stresses are taken according to $L$. Prandtl [10]: tangential stresses are constant, and normal stresses are linear (Fig. 4), the distribution of which is described by the formula

$$
\sigma_{y i}=\sigma_{y}\left(1+\frac{2 f \cdot x}{h}\right)
$$

where $\sigma_{y}$ - is the normal stress at the crack tip; $f$ - is the coefficient of contact friction; $h$ - is the height of the sample; $x$ - is the abscissa of the crack tip. The specific force according to the scheme (Fig. 4b), 
taking into account the yield of a part of the sample by the value of $2 x$ on the basis of formula (6) with the use of (5), is determined as

$$
p=\frac{2 \sigma_{y}}{c-2 x_{\xi}} \int_{0}^{L}\left(1+\frac{2 f \cdot L}{h}\right) d L=\sigma_{y}\left(1+\frac{f \cdot\left(0,5 c-x_{\xi}\right)}{h}\right),
$$

where $L=0.5 c-x_{\xi}$

The work [2] describes a method for determining the normal stress $\sigma_{\xi \gamma}$ at the crack tip as applied to the failure of specimens under uniaxial compression. The stress $\sigma_{\xi \gamma}$ at the crack tip at the TMECN $\xi_{1}$ is determined by the system of equations

$$
\begin{aligned}
& \left\{\sigma_{\gamma_{\xi}}=\frac{1}{\mu}\left[\frac{\left(k_{n}\left(1+\sin \rho \sqrt{1-b_{\xi}^{2}}\right)\right) \exp \left(2 \mu\left(\beta_{\xi}+\beta_{b}\right)\right)}{1-\sin \rho \sqrt{1-b_{\xi}^{2}}}-k_{b}\right]\right. \\
& k_{b}=\frac{\left(k_{n}+\mu \sigma_{\lambda \xi}\right)\left(1+\sin \rho \sqrt{1-b_{\xi}^{2}}\right)}{\left(1-\sin \rho \sqrt{1-b_{\xi}^{2}}\right) \exp \left(-4 \mu \beta_{b}\right)} ;
\end{aligned}
$$

where $k_{b}$ - is the effective shear stress at the point $b$ of the TMEKN $\xi_{1}$ on the contact bottom surface (Fig. 4)

$b_{\xi}=\frac{\tau_{x y}}{\mathbf{k}_{n}+\mu \sigma_{y_{\xi}}}=\frac{f \sigma_{y_{\xi}}\left(1-\frac{2 y}{h}\right)}{\mathbf{k}_{n}+\mu \sigma_{y_{\xi}}} ; \beta_{\xi}$ - the angle of rotation of TMEKN $\xi_{1}$ at the crack tip, equal to

$$
\begin{aligned}
& \beta_{\xi_{1}}=\frac{1}{2} \operatorname{arctg} \frac{f \sigma_{y_{\xi}}\left(1-\frac{2 y}{h}\right)_{\xi} \cos \rho}{\left(\mathbf{k}_{n}+\mu \sigma_{y_{\xi}}\right)\left(\sin \rho-\sqrt{1-b_{\xi_{1}}^{2}}\right)} \\
& b_{b}=-\frac{\tau \sigma_{c}}{\mathbf{k}_{b}+\mu \sigma_{y_{b}}}=-\frac{f \sigma_{b}}{\mathbf{k}_{b}+\mu \sigma_{y_{b}}}
\end{aligned}
$$


$\sigma_{y_{b}}=\sigma_{y}\left(1+\frac{2 f x_{b}}{h}\right)$ - normal stress at point $b ; x_{b}$ - abscissa of the crack tip at point $b ; \beta_{b}$ - is the angle of rotation of TMEKN $\xi_{1}$ at point $b$, equal to

$$
\beta_{b}=\frac{1}{2} \operatorname{arctg} \frac{b_{b} \cdot \cos \rho}{\left(\sin \rho-\sqrt{1-b_{b}^{2}}\right)}=-\frac{1}{2} \operatorname{arctg} \frac{f \sigma_{y_{b}} \cdot \cos \rho}{\left(\mathbf{k}_{b}+\mu \sigma_{y_{b}}\right)\left(\sin \rho-\sqrt{1-b_{b}^{2}}\right)} ;
$$

By formula (8) using formulas (9) - (13), we determine the specific force $\mathrm{p}$ by the iteration method. Specific force $\rho$ on TMECN $\xi_{1}$ (Fig. 5, curve 1) increases from the ordinate of the crack tip (as the tip moves away from the upper contact plane).

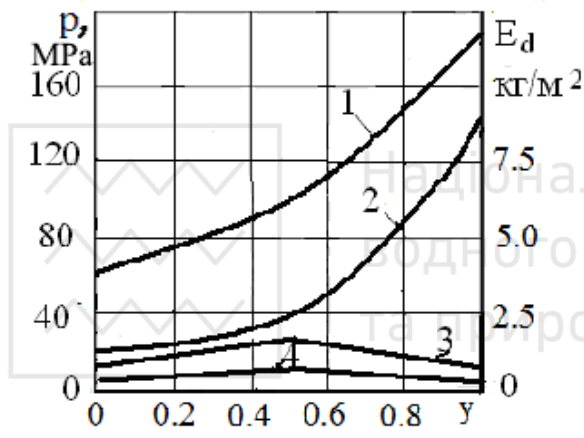

Fig. 5. Dependences of specific force and fracture energy on the ordinate of the crack tip at $k_{n}=10$ $\mathrm{MPa}, \rho=45^{\circ}, f=0.3, \mathrm{E}=2000 \mathrm{MPa}$

Using formula (8) from dependence (3), we determine the specific fracture energy of the sample (Fig. 5, curve 2). As can be seen, the specific energy of resolution at symmetric shear stresses is increasing

all the time.

Now let us determine the specific force and specific energy of destruction from the ordinate of the crack tip at asymmetric directions of contact tangential stresses (Fig. 6). In this case, we have positive signs on the contact planes with the development of cracks from top to bottom along TMEDN $\xi$ and from bottom to top along TMEDN $\eta$.

The formula for the distribution of contact normal stresses in this case has a different form

$$
\sigma_{y i}=\sigma_{y}\left(1+\frac{f \cdot x}{h}\right)
$$

Nevertheless, the formula (13) of the specific force remains the same. But in this case, the minus sign should be removed in formulas 
(12) and (13), and a minus should be introduced in formula (11) for $y>0.5 \mathrm{~h}$.

Then, in the exponential of expression (9), the parameters $\beta_{\xi}$ and $\beta_{b}$ will have negative signs and will significantly reduce the stress value at the crack tip $\sigma_{y}$.
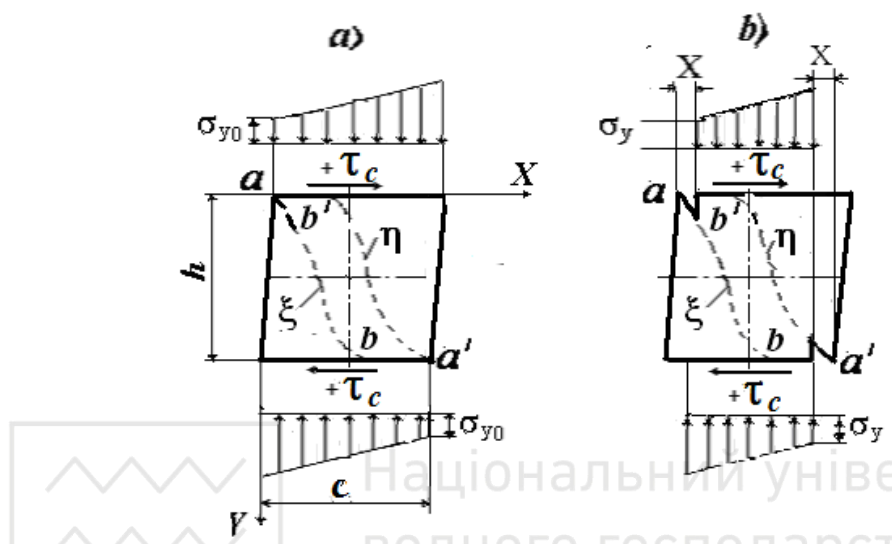

Fig. 6. Schemes of distribution of contact normal stresses and crack propagation under asymmetric contact shear stresses: $a$ - in an elastic state; $b$ - at the time of crack development

This, with asymmetrically directed contact tangential stresses, in comparison with symmetrically directed stresses during fracture of the sample, leads to a decrease in the specific force by up to 12 times (Fig. 5, curve 3). To calculate the specific energy of destruction, we use the well-known formula [11], which takes into account the energy consumption during oblique shear,

$$
E d=1 /(2 E) \cdot\left(p^{2}+2(1+v) f^{2} p^{2}\right) .
$$

The specific energy of destruction under asymmetric loading decreases 40-45 times (Fig. 5, curve 4).

Let us confirm this conclusion by constructing a diagram "longitudinal stress - longitudinal deformation" for this type of load and compare the latter with the diagram for symmetric loading. Let us first describe the method of constructing a diagram "longitudinal stress - longitudinal deformation" for a truncated-wedge fracture, which is also suitable for asymmetrically directed contact shear stresses. Knowing the values of stress $\sigma_{c} \mathrm{c}$ and longitudinal deformation $\varepsilon$ at each moment of the position of the crack tip in the 
sample, it is possible to construct an analytical dependence $\sigma_{c} \psi(\varepsilon)$. To do this, you need to determine the current value of the normal pressure on the branches of the conventional diagram. This pressure is

$$
\sigma_{c}=p S=p(c-2 x) / c
$$

where $S$ - is the ratio of the carrier to the starting site.

Now we need to define the second parameter of the diagram longitudinal deformation. We assume that at the crack tip the brittle rock material obeys Hooke's law. With knowledge of the values of the specific forces on the bearing part of the sample, the value of the longitudinal deformation can be determined according to Hooke's law

$$
\varepsilon=\frac{p}{E} \text {. }
$$

где $E$ - модуль упругости.

where $E$ - is the modulus of elasticity.

Now we build diagrams "stress - strain" for symmetric loading (Fig. 7, curve 1) and asymmetric directional contact shear stresses (Fig. 7, curve 2).

Comparing curves 1 and 2, one can confirm the conclusion already made. In addition, with asymmetric directional contact shear stresses after the entry of cracks into the opposite horizontal half of the specimen, self-sustaining failure occurs, that is, failure due to the previously accumulated elastic energy (Fig. 7, curve 2).

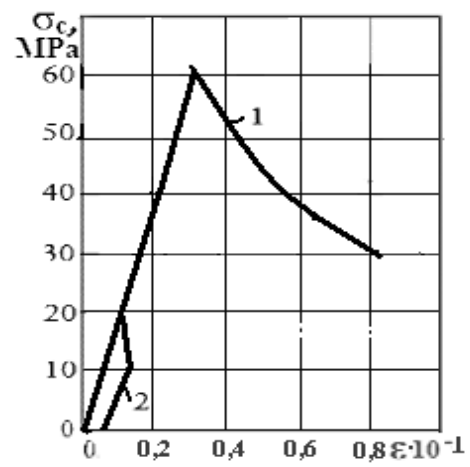

Fig. 7. Diagrams "stress - strain": with $k_{n}=10 \mathrm{MPa} ; \rho=45^{\circ} ; f=0.3 ; E=2000 \mathrm{~Pa}$ 
The conditions for loading rock pieces with asymmetric directional contact shear stresses (Fig. 7) are favorable from the point of view of energy consumption for destruction during crushing of brittle bodies.

These conditions, in our opinion, are partially realized in millstones and certain types of crushers.

Features of disintegration in crushers under normal and tangential loading

Consider the features of disintegration in crushers (Fig. 8).

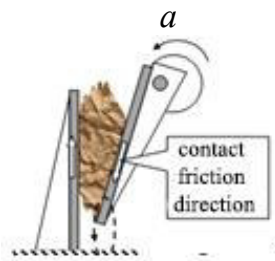

$b$
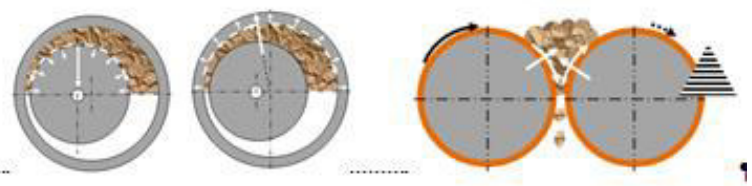

Pict. 8. Direction of friction forces in crushers: $a$ - in the cheek with a complex cheek movement; $b$ - in a cone; c) - in the roll.

In jaw crushers, the main difference between the crushing of material with a complex and simple movement of the jaw lies in the different orientation of the friction forces. Friction forces at the contact of the mass to be crushed with the cheeks are directed in one direction with a simple movement, and with a complex movement in different directions

With a simple movement of the cheek, the crushed mass is in conditions of uniaxial compression, and with a complex movement of the cheek - in conditions of sliding compression [12].

A cone crusher can be considered as a result of the development of a jaw crusher associated with the transition from flat to spatial motion of the crushing body (Fig. 8b). In a cone crusher, frictional forces in the vertical plane arise at the contact of the rock with both the outer and inner cones. They are oriented in the same way as in a jaw crusher with a simple jaw movement. In the horizontal plane, the total projection of friction forces at the contact with the crushed ore along the arc of the crushing cone is equal to 0 . Friction forces at the contact with the crushing cone are distributed in the same way as under the plate of a flat press - in different directions (Fig. 8b). The total projection of the friction forces at the contact with the crushed 
ore along the circular arc of the stationary cone is not equal to 0 [12]. Thus, as in a jaw crusher with a complex jaw movement, the rotation of the crushing cone provides crushing in an efficient sliding compression mode.

An increase in the efficiency of destruction in a two-roll crusher is carried out due to the transition from conventional to sliding compression by choosing a different speed of rotation of the rolls (Fig. 8c), as suggested, for example, by the Artyomovsk MachineBuilding Plant. According to [12], crushers with different (by 14$20 \%$ ) roll rotation speeds are used in the asbestos industry.

Creation of a more efficient mode of using friction characteristics provides a lower energy consumption of crushing [12]. Better energy intensity, along with other technological and operational advantages, the main one of which is the ability to work under a blockage, has led to the almost complete displacement of jaw crushers by cone crushers in the iron ore industry. Jaw crushers continue to be used in the building materials industry, such as crushing pieces of concrete structures.

\section{Output}

As a result of the development of mathematical models and analysis of the tension of the zone of interaction of the elements of the crusher with a piece of solid rock, it is established:

1. At the contact between the rock and the tool, two most stressed zones are noted: the contact surface, where the maximum principal stresses act, and the zone of maximum tangential stresses under the contact surface at a depth less than the dimensions of the contact area. At the boundary of the contact zone, an almost pure shear occurs, and ultimate deformations gradually accumulate in the material, which lead to the initial development of cracks.

2. Deformations arising during the action of the tool lead to a change in the shape of the surface even with a high hardness of the material and the actual dimensions of the contact pads increase. With an increase in the tangential load, the zone of uniform compression of the material decreases, the depth of the most stressed point approaches the contact surface. There is a zone of action of shear deformations, which are the decisive factor in the initiation of a crack.

3. As the cracks develop, the specific force at symmetric contact tangential stresses increases all the time, and at asymmetrically 
directed contact tangential stresses increases from the ordinate of the crack tip to the horizontal axis of symmetry, then decreases, while the maximum value of the specific force in the first case is 8-10 times higher than in the second case.

4. Specific fracture energy (by the example of a sample) at asymmetrically directed contact shear stresses in comparison with symmetric loading is reduced by up to $40-45$ times.

5. The conditions of asymmetrically directed contact shear stresses during crushing of brittle bodies are more favorable from the point of view of energy consumption for fracture in comparison with symmetric contact shear stresses.

6. The above examples of the use of contact friction forces to create the so-called sliding compression in crushers confirm the effectiveness of the destruction of fragile bodies by asymmetrically directed contact shear stresses and show the way to reduce the energy intensity of disintegration when creating appropriate machines.

\section{References}

1. V.S. Blohin, V.I. Bolshakov, N.G. Malich Osnovnye parametry tehnologicheskih mashin. Mashiny dlya dezintegracii tverdyh materialov: Uchebnoe posobie ch.1 - Dne-propetrovsk; IMA - press.- 2006. - 404s.

2. Vasilev L.M., Vasilev D.L., Malich N.G., Angelovskij A.A. Mehanika obrazovaniya form razrusheniya obrazcov gornyh porod: Monografiya.- Dnipro, IMA-press.-2018-172s.

3. N.G. Malich Nauchnye osnovy razvitiya rascheta parametrov mashin dlya zemlyanyh rabot $\mathrm{v}$ gorno-metallurgicheskom komplekse. MonografiyaDnepropetrovsk, IMA-pres.-2010 -380s.

4. Lejbenzon L.S. Kurs teorii uprugosti.-M.-L.:Gosizdat,1977.

5. Vinogradov V.V. Geomehanika upravleniya sostoyaniem massiva vblizi gornyh vyrabotok / V.V. Vinogradov. - K.: Naukova dumka, 1989. - $192 \mathrm{~s}$.

6. Kirnichanskij G.T. Elementy teorii deformirovaniya i razrusheniya gornyh porod / G.T. Kirnichanskij. - K.: Naukova dumka, 1989. - 184 s.

7. Vasilev, L.M. Uchet kontaktnogo treniya $\mathrm{v}$ zadache o razrushenii gornyh porod szhatiem /L.M. Vasilev, D.L. Vasilev // FTPRPI. - 2015. - № 3. - S. 48- 56.

8. Zorin A.N. Mehanika i fizika dinamicheskih yavlenij v shahtah / A.N. Zorin, V.G. Kolesnikov, K.K. Sofijskij. - K.: Naukova dumka, 1979. - 169 s.

9. Baron A.I. Gornotehnical porodovedenie / L.I. Baron. - M.: Nauka, 1977. - 324 s.

10. Panasyuk, V.V. Predelnoe ravnovesie hrupkih tel s treshinami / V.V. Panasyuk. - K.: Naukova dumka, 1968. - $246 \mathrm{~s}$.

11. Storozhev M.V. Teoriya obrabotki davleniem / M.V. Storozhev, E.A. Popov - M.: Mashinostroenie. 1967 - 423 s. 
12. N.G. Malich, L.M. Vasilev, O.A. Usov Issledovanie vliyaniya parametrov nagruzheniya na raspredelenie napryazhenij, dejstvuyushih pri razrushenii shihtovyh materialov v drobilkah // Metallurg. i gor-norudn. prom-st.-2015.-№7.-S.99-106.

https://doi.org/10.31713/m1029

\title{
RESEARCH OF THE POSSIBILITIES OF USING URBAN GREEN SPACES IN DONBASS CITIES TO RECREATE THE RESOURCE STATE OF THE MINING REGION
}

\author{
V. Sokolenko \\ Volodymyr Dahl East Ukrainian National University, Candidate \\ of technical science, Associate Professor, Ukraine \\ M. Filatiev \\ Volodymyr Dahl East Ukrainian National University, \\ Doctor of Engineering Sciences, Associate Professor, Ukraine

\section{K. Sokolenko} \\ Volodymyr Dahl East Ukrainian National University, \\ Postgraduate student, Ukraine

\section{S. Piddubnyi} \\ Volodymyr Dahl East Ukrainian National University, \\ Senior Lecturer, Ukraine
}

\section{Annotation}

Ukrainian Donbass has crossed the peak of extensive growth. Today this industrialized urbanized region has faced with a complex of problems. Sustainable urban development cannot be based only on the exploitation of natural raw materials. The task is to build a balanced model for the development of an industrial region, when the criteria for success are the quality of the environment, urban development, human potential. The exploitation of the resource base must be compensated for by the preservation of the environment. The natural landscapes of Donbass have been partially destroyed, partially changed by economic and industrial activities. There is a need to reproduce adapted green landscapes of cities in order to improve the ecological situation and restore the landscape and recreational potential of the territories. Alchevsk is in many ways the median city of Donbass. The subject of the study has chosen the green spaces of the city of general use, limited and special purpose for a period of more than 25 years, that is, the duration of the General Plan. The goal of research is to determine the species composition of green spaces typical for the cities of the Luhansk region and the establishment of a group of plants that are maximally adapted to independent growth in the urban landscape. The geographical, climatic and orographic characteristics of the city are considered, 